O texto se compóe de duas partes. Na primeira, as autoras apresentam o Instituto Therapon Adolescência, uma instituição especializada no atendimento de adolescentes com transtornos emocionais graves. Nesta apresentação, estão descritos a concepção de saúde mental, o cotidiano e o espaço psíquico da instituição. Em seguida, mostra-se como a instituição funciona na prática, através da apresentação de um caso clinico. Trata-se de uma paciente que se apresentava com um comportamento "delinqüente", cujo sentido escapava ì equipe até poder ser esclarecido na terapia de família. O relato aborda, ainda, o modo de funcionamento do espaço psíquico da instituição por meio das reunióes clínicas. Tratamento institucional de adolescentes; delinqüência como sintoma; terapia familiar; espaço psíquico da instituiçăo, grupalidade

THERAPON ADOLESCENT INSTITUTE: INSTITUTIONAL TREATMENT FOR SEVERE EMOTIONAL DISORDERS

The text is composed of two parts. In the first the authors present the Therapon Adolescent Institute specialized in attending adolescents with severe emotional disorders In this presentation are described the concepts of mental health, daily routine and the psychic space of the institution. The authors next show how the institute functions in practice by the presentation ot a clinical case. This case is about a patient with delinquent bchaviour, the meaning of which only became clear in the family therapy. The presentation also focuses on the functioning of the psychic space of the institution through the clinical meetings.

Institutional treatment for adolescents; dclinquency as a symptom; family therapy; institution's psychic space; groupality

\section{INSTITUTO \\ THERAPON \\ ADOLESCÊNCIA: TRATAMENTO INSTITUCIONAL \\ DE TRANSTORNOS EMOCIONAIS GRAVES}

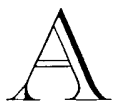

Marion Minerbo

Priscila de Oliveira Galvani

desenvolvimento do ser humano. A delicada desenvolvimento do ser humano. A delicada interação entre o adolescente, sua família, a escola e a sociedade é decisiva durante este processo. Em alguns casos, o turbilhão emocional típico desta fase cristaliza-se na forma de patologia, com sintomas dos mais variados tipos: fragilidade emocional extrema, dificuldades escolares graves, isolamento e marginalização social, relacionamento familiar explosivo, depressão, fobias, distúrbios alimentares, distúr-

Psicanalista, membro efetivo da Sociedade Brasileira de Psicanálise de São Paulo, doutora em Psiquiatria pela Escola Paulista de Medicina, sócia fundadora e atual presidente do Instituto Therapon Adolescência.

Psicóloga, sócia do Instituto Therapon Adolescência, terapeuta do projeto Semear, ex-educadora da Escola Viva. 
bios do comportamento em geral, delírios e alucinações. Estes adolescentes acabam abandonando a escola e ficam isolados do ponto de vista social. O círculo vicioso das relações afetivas patogênicas vai se fechando em torno desses jovens, tornando o prognóstico cada vez mais sombrio.

O Instituto Therapon Adolescência é uma organização sem fins lucrativos criada para atuar junto a adolescentes, familiares, profissionais da educação e da saúde mental, no trabalho de recuperação psicológica, pedagógica e na reintegração social do jovem com transtornos emocionais graves. A reconstrução de relações humanas saudáveis entre o adolescente e seu meio ambiente exige um determinado modelo assistencial em saúde mental. Implantar este modelo, aperfeiçoá-lo e multiplicá-lo são as nossas metas mais amplas.

\section{UMA CONCEPÇ̃̃O DE SAÚDE MENTAL}

Em nossa concepção, a atuação dos profissionais da saúde mental não pode se restringir à eliminação dos sintomas. Nosso foco é a pessoa que sofre. Entendemos o sintoma como um grito de socorro do sujeito psíquico. Diante de situações de violência emocional, geralmente vividos desde a tenra infância, o sujeito que se encontra num impasse lança mão de um recurso extremo: o de mutilar a subjetividade. É uma maneira de escapar à realidade intolerável. Esta defesa "suicida" resulta na doença mental e seus sintomas.

Nesta perspectiva, além de tratar dos sintomas, procurando minimizar o sofrimento do paciente, é preciso reconstruir sua subjetividade. Isto significa ajudá-lo a encontrar uma saída ou, ao menos, um sentido para aquilo que ele experimenta como uma realidade intolerável, marcada por uma violência emocional extrema.

Se o sujeito adoece, entre outras razões, numa malha de relações afetivas patogênicas, buscamos a reconstrução de vínculos humanos saudáveis em espaços de convivência coletivos. O Instituto Therapon Adolescência é o ponto de partida para impulsionar o sujeito para a vida. Esperamos oferecer um neo-meio-devida, uma realidade mais acolhedora, um lugar em que os conflitos possam ser abordados, de modo que ele possa, aos poucos, recuperar as partes mutiladas de sua personalidade (dependendo do prognóstico).

Os projetos terapêuticos são personalizados e construídos a partir de atividades e intervenções que façam sentido para cada um. A família é sempre incluída no tratamento, o que é, aliás, uma 
condição para aceitarmos o jovem na instituição.

Nosso objetivo consiste também em minimizar a necessidade de internações em hospitais psiquiátricos tradicionais, lutar contra a cronificação do doente mental numa postura política antimanicomial; prevenir condutas auto e hetero-agressivas de natureza variada, e encontrar um modo de vida possivel para esses jovens que apresentam necessidades especiais.

Nossa concepção de cura envolve a conquista do maior grau possível de autonomia pelo adolescente. Um dos sinais inequívocos dessa autonomia é a construção de um projeto de vida a partir de um desejo próprio. Para tanto é imprescindível que ele continue sua escolarização durante o tratamento, de modo a poder retornar à rede escolar assim que possivel. É com este intuito que a Escola Therapon vem complementar o tratamento. É nossa maneira de ir ao encontro do Estatuto da Criança e do Adolescente, atendendo aos seus direitos enquanto ser humano e cidadão.

\section{COTIDIANO E ESPACCO PSÍQUICO DA INSTITUIÇÃO}

O paciente que nos é encaminhado passa, inicialmente, por um processo de triagem. Os pais ou responsáveis, juntamente com o paciente, são avaliados por uma dupla de terapeutas. Se o caso não pode ser atendido por nós, procuramos encaminhá-lo a outros serviços. Se ele se encaixa em nossas possibilidades de atendimento (patologias, faixa etária), o processo de triagem continua: o paciente passa por um período de experiência, freqüentando o Therapon durante uma ou duas semanas. Seu desejo de se tratar em nossa instituição é fundamental para a continuidade do processo. Nesse período ele poderá ser observado mais de perto pelo conjunto da equipe.

Em seguida, o caso é discutido por todos os terapeutas em reunião clínica. Discutimos a hipótese diagnóstica, avaliamos o prognóstico, especialmente a possibilidade de o paciente se beneficiar com o tipo de tratamento que temos a oferecer, dentro de uma abordagem psicanalítica. Avaliamos também sua possibilidade de convivência com o grupo de pacientes que já freqüenta a instituição; se há um mínimo de aceitação mútua e de participação nas oficinas terapêuticas. Se o paciente vem encaminhado com graves dificuldades escolares, consideramos a possibilidade de ele passar a freqüentar a Escola Therapon em vez de sua escola de origem, até que possa retornar a ela. Neste ponto, esboçamos um projeto terapêutico mínimo, que será reavaliado sempre que o caso daquele paciente for discutido nas reuniōes clínicas subseqüentes. Nesta reunião clínica encerramos o processo de triagem. Quando o caso é aceito, dois terapeutas são designados para serem a referência do paciente e de sua família junto à instituição.

Acreditamos que a comunidade seja um fator terapêtico em si mesmo, desde que observados alguns 
cuidados com o espaço psíquico da instituição. Temos dois diretores clínicos: um vinculado ao Conselho Regional de Medicina, e outro, ao Conselho Regional de Psicologia. Estes profissionais respondem legalmente pela instituição, porém não exercem qualquer tipo de poder, seja sobre a instituição, seja sobre os técnicos. Nossa organização interna é horizontal. Isto significa que cada dia da semana é dirigido e coordenado por uma mini-equipe. Assim, algumas pessoas compõem a equipe $\mathrm{da}$ segunda-feira, e, juntas, detêm o poder e são responsáveis por tudo o que acontece na segunda-feira. A equipe da terça-feira toma conhecimento das ocorrências/intercorrências da segunda-feira, através de um caderno de passagem. Considera-se um "atravessamento da autoridade" qualquer decisão tomada individualmente, à revelia da mini-equipe, ou pela equipe de um outro dia. Estas diferenças são entendidas como sintoma da equipe e são discutidas enquanto tal nas reuniões clínicas. Muitas vezes, estes atravessamentos mostram ser uma repetição do relacionamento entre os pais (um dos cônjuges desautorizando o outro, numa relação totalitária). A ideologia que sustenta este tipo de organização horizontal do poder consiste em criar e manter, tanto quanto possível, um ambiente psíquico democrático. Entendemos que a capacidade de preservar, ao longo do tempo, o respeito ao outro e à comunidade, é um fator terapêutico em si mesmo. As eventuais lutas de poder são entendidas como um adoecimento do espaço psíquico da instituição, cujos reflexos nefastos sobre o tratamento dos pacientes não tardam a se manifestar.

Temos, semanalmente, duas reuniões clínicas em que participam tanto a equipe pedagógica (da Escola Therapon) quanto a dos psicoterapeutas. Nestas, avalia-se a evolução de cada caso, redirecionando o projeto terapêutico quando necessário. Discute-se, também, o relacionamento dos técnicos entre si. Em outras palavras, temos um espaço para cuidar do mais importante: a saúde mental da equipe, que é nosso principal instrumento terapêutico. Além disto, a relação entre técnicos e pacientes, e destes entre si, é amplamente discutida por toda a equipe. A compreensão mais refinada do caso conduz a um aperfeiçoamento do projeto terapêutico, bem como do manejo técnico no dia-a-dia.

A terapia familiar é conduzida pelos dois terapeutas responsáveis pelo caso. A freqüência (semanal, quinzenal, mensal) depende de cada caso, e a decisão é tomada em reunião clínica. A terapia de base psicanalítica visa, principalmente, a 1) permitir à família perceber sua própria dinâmica; 2) perceber de que maneira o filho se oferece como continente, ao mesmo tempo em que expressa, através de seus sintomas, a patologia familiar e 3) como esta interação "interessa" à família e perpetua o sintoma; 4) tomar consciência da construção transgeracional do sintoma pela história da família.

Finalizando a apresentação da instituição, cabe mencionar que, em vista das várias atividades acima descritas - oficinas terapêuticas, atendimento familiar, escola, acompanha- 
mento terapêutico -, foram nascendo espaços supervisivos, ou melhor, espaços de interlocução específicos para cada modalidade clínica.

\section{BETH}

\section{Triagem}

Beth foi encaminhada pelo NAE (Núcleo de Ação Educativa) com uma longa história de "problemas escolares e de relacionamento”. Várias tentativas de tratamento psicológico, bem como diversas transferências escolares, já faziam parte do currículo desta garota de 14 anos. Ela brigava muito e nem mesmo as classes especiais da rede municipal de ensino sabiam o que fazer com ela. A paciente veio para freqüentar a Escola Therapon. Já na triagem a mãe ficou sabendo que a escola é um complemento ao tratamento institucional, de modo que ela teria que freqüentar o hospital-dia. Cida concordou.

Que ingenuidade, a nossa! Este relato vai mostrar como fomos descobrindo a enorme distância que há, neste atendimento, entre concordar e concordar. $O$ processo trilhado por todos, equipe e família, para iniciar o tratamento - só agora podemos ver isto - , é o próprio tratamento. Mas não nos adiantemos.

Alguns dados de história. Beth é uma garota que foi adotada como forma de pagamento de uma promessa. Os três filhos de Cida sobreviveram a um grave acidente de carro e ela sentiu que a melhor maneira de agradecer a Deus pelo milagre seria fazer um bem a outra criança. Ela havia feito uma laqueadura porque seus partos haviam colocado sua vida em risco. Assim, esta "outra criança" teria de ser adotada. Beth tinha quatro meses, estava praticamente abandonada pela mãe biológica no chão, no terreiro de terra batida, nua, sobre um pano ("para a mãe biológica não ter que trocar as fraldas"), desnutrida, com a pele cheia de feridas, quando Cida levou-a para casa.

O berço novinho, limpo e confortável, Beth nunca quis usar. Assim que Cida a colocava ali, o bebê começava a chorar desesperadamente $\mathrm{e}$ só se acalmava no colo. "Ela vivia grudada em mim; onde eu ia, ela ia”, embora Cida afirmasse também que não pôde criar Beth como havia criado seus outros filhos porque trabalhava muito, das $6 \mathrm{~h}$ à meia-noite.

Beth tem problemas desde pequena. Foi alfabetizada pela irmã, que é professora. Sempre foi revoltada e agressiva, especialmente com a mãe, que suporta tudo estoicamente. Por outro lado, quando está apenas com a mãe, Beth é uma menina tranqüila. Ela conhece toda a história aqui relatada, exceto a parte de "pagar uma promessa”. Cida separou-se do pai de seus filhos há 12 anos, e este sumiu, de modo que Beth não teve pai. Os irmãos são bem mais velhos do que ela: 24, 26 e 28 anos.

\section{O cotidiano na instituição}

Beth começa a freqüentar o Therapon em agosto de 2001. Corpulenta, clara de pele, não parava de mexer e fazer rabo de cavalo em seus cabelos "pixaim". Roupas enormes e desleixadas eram calculadas para es- 
conder seu corpo. Olhinhos espertos de sagüi perscrutavam tudo atentamente e demonstravam, no mais das vezes, ódio de tudo e de todos, inclusive dela mesma.

Durante o período de experiência, mostrou-se falante e participativa para tornar-se, em seguida, francamente desbocada. Em pouco tempo transformou-se num furacão malhumorado e briguento. Os pacientes temiam seus rompantes de violência. Certa paciente, mais frágil e jovem do que ela, era o alvo predileto de suas agressões físicas e verbais. Sua presença era disruptiva, turbulenta, impedindo o funcionamento das oficinas terapêuticas. Quanto à Escola, nos primeiros meses aceitava estar em sala de aula com outros pacientes, porém rapidamente foi se isolando até recusar-se a participar de quaisquer atividades pedagógicas. Apresentava também comportamentos autoagressivos: "mascava" objetos cortantes e mordia compulsivamente a bochecha por dentro. Tudo isto não nos impedia de reconhecer qualidades humanas importantes, soterradas por este sistema defensivo, por ora impenetrável. Imaginávamos, do outro lado, uma dor psíquica atroz.

Tentamos colocar limites de várias maneiras: firme, carinhosa, oferecendo espaços individualizados. As tentativas de aproximação e de construção de uma convivência possível funcionavam até certo ponto, mas de repente desandavam, sumiam num "Triângulo das Bermudas", sem que fosse possivel compreender o que acontecera. Por outro lado, chamava de "pai", era carinhosa e mesmo respeitosa com o coordenador da Ofici- na da Palavra, da qual participava com prazer. Uma das terapeutas era seu "diário", outra era sua "mãe". Porém quase sempre queria estar, justamente, com quem não estava disponível naquele momento.

Sua agressividade, contudo, tinha uma característica notável: as ofensas não eram sentidas por nenhum dos terapeutas como dirigidas à pessoa deles. A sensação era de uma revolta sem objeto definido, ou melhor, dirigida a um interlocutor ausente da cena. Talvez a agressão fosse à função que ocupávamos - "cuidar dela”. Era o que acontecia na prática: ela se empenhava em tornar o "cuidar dela" uma missão impossível.

Com o tempo, a escalada da violência nos levou a um impasse. Por um lado, não podíamos aceitar que agredisse continuamente outros pacientes. Por outro lado, não podíamos realizar nosso desejo de mandála embora, visto que seu comportamento visava justamente obter este tipo de resposta, confirmando sua fantasia de não existir no mundo um lugar para ela. Certo dia avançou sobre um terapeuta, rasgando-lhe a camiseta. Foi a gota d'água.

\section{Rcuniões clínicas}

Embora ocupasse há meses muito espaço nas discussões clínicas, um sentimento de impotência e perplexidade pesava sobre a equipe. Uma coisa era certa: Beth não estava sendo tratada. A psiquiatra propôs um tratamento medicamentoso (Zoloft), pois muitas vezes a depressão na adolescência se traduz por comportamentos dessa natureza. O fármaco controlaria os sintomas, diminuindo 
seu sofrimento e o dos que a rodeavam. Porém, isso ainda não era tratá-la, do ponto de vista psicanalítico.

Verificamos que não era possível pensar um projeto terapêutico, porque nos faltava um chão sobre o qual organizar um contrato eficaz com a família. A terapeuta lutava em vão para conseguir que a mãe viesse nos dias combinados. Como ficou dito acima, estávamos num impasse: a equipe esgotara seu arsenal terapêutico, a terapeuta não avançava um passo no tratamento da família, e Beth fazia o possivel para ser mandada embora.

A saída do impasse passa por um momento de auto-interpretação grupal: a equipe percebe que incumbira a terapeuta de fazer algo em seu trabalho com a família (um milagre?) que tornasse possível ao grupo tolerar Beth no dia-a-dia. O milagre demandado reproduzia, como veremos, o mito de origem desta paciente. Finalmente, surge uma proposta terapêtica, agora sustentada por toda a equipe.

Em primeiro lugar, formar uma dupla para atender a família. Desse modo, a terapeuta já não estaria sozinha fisicamente, na sala de atendimento, nem psiquicamente, pois havia uma dupla que contava com o projeto terapêutico elaborado em conjunto pela equipe.

Em segundo lugar, incluir na terapia os irmãos, que já são adultos. Seria uma tentativa de ajudar a mãe a se comprometer com o tratamento, fazendo com que ela também tivesse o respaldo de um grupo: o grupo familiar.

Por fim, re-contratar o tratamento. Pois era evidente que, apesar de a māe ter concordado com as condições propostas, ela não se havia implicado no tratamento, e muito menos Beth. Ambas não haviam compreendido que este dependia delas também e era preciso deixar isto claro. A atitude terapêtica consistia em dizer a Cida e Beth que, por enquanto, esta não viria mais ao Therapon. Não se tratava de uma suspensão com sentido de punição, mas de uma suspensão no tempo - dar a todos o tempo necessário para desfazer um círculo vicioso negativo e, principalmente, para tentar construir um sentido para o que vinha acontecendo. Em outras palavras, era preciso conseguir interpretar a transferência que a paciente fazia com a instituiçāo. Enquanto isto não acontecia, ao menos um manejo clínico se impunha: era preciso demonstrar que a equipe tinha realmente atingido seus limites. $O$ tratamento continuaria na forma de terapia familiar semanal - até então vínhamos usando expressões mais vagas, como "atendimento familiar".

\section{Terapia familiar}

O re-contrato se deu em vários níveis. Foi necessário despojarmo-nos explicitamente de toda onipotência que porventura tivésse- 
mos assumido, na transferência. Dissemos que, por enquanto, não sabíamos o que fazer com Beth e pedimos ajuda à mãe, afirmando que, sozinhos, nada podíamos fazer. Nossa situação, aliás, era idêntica à sua, que obviamente precisava da ajuda dos filhos para sustentar uma posição com a filha. Esta postura já tinha um valor terapêutico, na medida em que nos recusávamos a aderir ao mito de origem de Beth, reconstruído a partir do próprio atendimento familiar. Quando Cida nos relata como salvou Beth da morte (o bebê largado sobre o pano no chão), vai ficando claro que, tanto para a mãe quanto para a filha existe um objeto onipotente, um anjo da guarda que está ali para salvar Beth da morte e agüentar "qualquer coisa" que ela faça. Quando formulamos em palavras esta fantasia compartilhada, Cida relata várias situações em que é obrigada a salvar Beth de situações muito perigosas. Dissemos que nós não podíamos, não desejávamos, nem acreditávamos ser saudável que alguém - mãe ou instituição - se propusesse a agüentar "qualquer coisa". Beth saía da sala batendo portas de raiva quando tocávamos no assunto.

"Ela tem que agüentar qualquer coisa sim, porque ela é minha mãe! Vocês não têm que se meter, nem fazer a cabeça dela!"

"Ela é meu anjo da guarda. Se ela morrer, eu morro junto!".

Trabalhamos com a mãe a diferença entre salvar e acolher. Os filhos, Rodrigo e Roberta, colaboravam, mostrando à mãe quanto ela protegia Beth, numa atitude muito diferente da que tinha tido com eles quando eram crianças. Por que a diferença? Além disso, disseram-lhe que era carinhosa demais com Beth, atitude que não combinava com sua personalidade. Novamente, por que ser diferente com ela? Era Beth quem respondia: "ela é falsa, na verdade não gosta de mim, me protege por dó”. As coisas começavam a ser ditas.

Certa vez, quando Beth dizia que não queria ficar no Therapon, porque não era louca ("Não é mesmo, mãe?") a mãe, numa atitude diferente da que adotara até então, disse: "você é louca sim, só louco faz as coisas que você faz!”. Era a primeira vez que a víamos recusar-se a ser anjo da guarda, apesar dos pedidos da filha.

As sessões deste período se iniciavam com relatos das "delinqüências” de Beth. Roubara dinheiro da família e até mesmo da empregada, andava em más companhias, chegou a pedir esmolas na rua para comprar cigarros. Cida tinha uma postura firme, condenando suas transgressões, acusando a mãe de outra garota de ser conivente com ela - a vizinha com quem Beth “aprontava”. Disse, inclusive, que denunciaria Beth à Febem se necessário, porque ela precisava aprender a diferença entre o certo e o errado. Sentíamos 
que ela realmente estava preocupada com o futuro de sua filha, e que já não sabia como fazer para cuidar dela.

A mãe apostava que Beth tinha jeito, que é uma boa menina; já o irmão achava que delinqüência podia ser coisa genética - afinal, ele e os irmãos eram pessoas corretas. Enfim, as vozes familiares expressam uma ambigüidade na maneira de olhar para Beth. Uma associação de Cida é bem significativa. Um rapaz, assassino, foi condenado à morte. Pouco antes expressou seu último pedido: queria ver a mãe. Quando ela chegou para se despedir, o filho pediu que the estendesse a mão e então the dá uma mordida de tirar pedaço. E diz: mãe, se eu sou assim, a culpa é sua, pois você sempre fechou os olhos para todas as coisas erradas que eu fiz, desde pequeno. Moral da história: "eu não sou como esta mãe, pois não deixo passar nada”.

Veremos, mais adiante, como o trabalho avança até que surja sua maior angústia: ter criado uma delinqüente por excesso de complacência complacência cuja raiz não é difícil de imaginar. Nesta época, perguntávamo-nos se, afinal, não estávamos mesmo diante de uma psicopatia.

Mas o tipo de material começa a mudar. O cunhado da irmã, que é problemático, teve que fazer terapia para reunir a coragem necessária para fazer certa pergunta à mãe, sobre suas origens. Beth, ouvindo isto, diz à mãe: "eu também tenho uma pergunta para te fazer”. Todos aguardam a pergunta, mas ela desconversa.

Veio o ponto de virada. Cida conta uma história que Beth - que estava fora da sala, num de seus acessos de fúria - não conhece. Sua mãe biológica deu dois filhos ao mesmo tempo: o bebê (Beth) e o mais velho, de 11 anos, que não serviam para pedir esmola. Ela ficou com o bebê, e um casal que não tinha filhos, e que já cuidava e convivia com o menino havia tempos, ficou com ele. Foi só legalizar a situação, assinarem os papéis da adoção, para que o menino, até então dócil e carinhoso com o casal, se transformasse numa praga. Passou a ter um comportamento rebelde, não se sentava mais em seu lugar à mesa, recusava tudo o que o casal the oferecia. Neste momento, entra Beth. Peço à mãe que repita a história. Ela ouve atentamente e exclama: "pois eu o entendo perfeitamente, para que ele vai querer pais adotivos, se tem pais biológicos? Ele ficou revoltado por ter sido dado, e por ter sido adotado".

E então ela começa a chorar, dizendo que preferia mil vezes viver com sua família biológica, mesmo pobre, mesmo que fosse para pedir esmolas, a viver com esta família rica. Ela não precisava, não queria as coisas que the davam. "Você não gosta de mim, me pegou por pena, fica comigo por dó". Cida chorava, o irmão estava boquiaberto. Beth terminou seu discurso dizendo que iria morar com eles, e que pretendia infernizar a vida deles também, por a terem dado em adoção. Pela primeira vez, víamos Beth emocionada, num desabafo penoso, angustiado, em que expressava aquilo que vivia e calava havia tanto tempo.

Dissemos a Beth que era muito importante ela ter dito isto, que ela 
realmente compreendeu aquele menino, que isto devia estar engasgado havia muito tempo, e agora o comportamento dela fazia sentido. Ao que ela retruca: "até que enfim você disse alguma coisa que preste, nesta terapia”. Também foi necessário dar uma sustentação a Cida, dizendo a Beth que, para sua mãe, era difícil ouvir seu desabafo. Mas Cida diz simplesmente: "é seu direito conhecer sua mãe biológica”. Em outra ocasião, ainda elaborando o que acabara de ouvir: "eu sempre soube que um dia ela ia me dizer isto; mas eu acho que é bem pior esconder dos filhos".

A partir disso, foi possível ir construindo um sentido para a transferência. Num nível mais superficial, Beth atuava para ser "devolvida". Mas ela parecia saber que Cida estava presa a ela por uma espécie de dó primordial, fundante da relação mãe-filha - a julgar pela descrição, sempre repetida, do bebê largado sobre um pano no chão do terreiro. Beth testava os limites do "amor materno", esperando uma confirmação de sua fantasia: sua mãe não a amava, apenas tinha dó dela. Ela era habitada por um enigma insolúvel: por que havia sido adotada, se a mãe já tinha três filhos? Por que alguém - sua mãe, nós - propunha-se cuidar dela? Mesmo que recebesse uma demonstração de amor, seja de Cida, seja de outras pessoas, ela imediatamente suspeitava que não se tratava de amor, mas de dó. A prova dos nove consistia em tentar transformar o suposto amor em raiva. Se isto acontecesse, era amor mesmo, visto que entre mães e filhas é comum isto acontecer. Se ele não se transformasse em raiva, não era amor, mas dó. E dó, ela não queria, era revoltante ser objeto de pena da própria mãe. E, assim, Beth infernizava a vida de Cida, mas como ela suportava tudo estoicamente (a promessa!), protegendo-a e acobertando-a como os irmãos haviam apontado, Beth comprovava suas fantasias. Habilmente, ela havia colocado Cida numa armadilha: "mãe tem que agüentar calada qualquer coisa, ou então, confessar que me agüenta por dó". Por fim, se Cida havia pretendido pagar uma promessa, adotando-a, Beth se encarregava de realizar, inconscientemente, o desejo materno.

As coisas começavam a se esclarecer. Se o fundamento deste amor adotivo é o dó, e se ela, Beth, não passava do pagamento de uma promessa, evidentemente não podia aceitar o berço novinho de Cida, nem o lugar que lhe oferecíamos no Therapon. Isto seria o mesmo que renunciar para sempre à família biológica idealizada, a um suposto "amor materno verdadeiro", este que não se confunde com dó. Beth confessou que batia em Maria (que é das poucas crianças não-adotadas do Therapon) porque "tenho ciúme do amor da mãe dela, e também bati no Mateus (sobrinho) pelo mesmo motivo". 
Enfim, depois do desabafo de Beth, imaginávamos continuar conversando sobre a visita de Beth à sua família biológica. Soubemos que o assunto "visitar a família" tinha sido amplamente debatido em casa, com os irmãos, cunhados, madrinhas etc. No início Beth queria se mudar, de mala e cuia. Depois achou melhor ir sem suas coisas - o aparelho de som, a bicicleta. Por fim, o tema foi se esgotando e parou de falar no assunto. Neste meio tempo, ela pediu para voltar a freqüentar o Therapon: "estou cheia de ficar em casa vendo televisão”.

Seu comportamento, na terapia de família, havia mudado da água para o vinho. Pela primeira vez sentou-se no mesmo sofá das terapeutas, em lugar de ficar isolada, perto da porta, prestes a se retirar furiosa quando necessário. Por algum tempo, ela esteve verdadeiramente divertida e agradável.

Para concluir o relato sobre a terapia de família, vale a pena incluir uma passagem em que o dó faz sua entrada em cena de maneira mais explícita. Vínhamos tendo problemas para receber o pagamento estipulado com a mãe pelo tratamento. Cida argumentava (com a secretária) que não era justo pagar o preço integral se Beth ainda não freqüentava todas as atividades (tínhamos proposto um retorno gradual ao Therapon). $\mathrm{O}$ assunto dinheiro foi encaminhando a conversa às suas críticas ao tratamento. Acusava-nos de sermos muito complacentes e de fazermos tudo o que Beth queria. Temia que este "tratamento light" prejudicasse sua filha, acentuando seu com- 


\section{Experiências Institucionais}

portamento transgressivo. A projeção de sua própria complacência é notória. Lembramos sua história do assassino que mordeu a mão da mãe, acusando-a de tê-lo transformado nisso. Ela então diz que lamenta não ter sido dura e firme em sua educação, como foi com os outros filhos. "Por quê?" é nossa pergunta seguinte. Fica sem resposta e balbucia coisas do tipo: ... ela era muito doentinha ... eu quase nunca estava em casa ... ela não teve pai. Já não era possível disfarçar: ela morria de dó e não conseguira ser dura e firme com uma criança que carregava a marca do abandono filicida. Embora Cida não tenha dito nada disso, ficando nas desculpas esfarrapadas, Beth cobre sua cabeça com uma almofada e começa a morder a parte de dentro de sua bochecha, que é sua maneira de expressar sua revolta.

\section{Concluindo}

Depois da sessão do desabafo, a equipe decide em reunião clínica que Beth pode retomar aos poucos as atividades no Therapon. Na primeira semana, todos - terapeutas e pacientes - comentam a "nova Beth". Na oficina de artes, estávamos fazendo um painel coletivo e havia uma árvore que Maria estivera desenhando. Beth preenche os espaços em torno de seu desenho, respeitando o espaço plástico de sua rival. Parecia-nos que ela finalmente se implicara no tratamento, mais de seis meses após sua entrada no Therapon.

Porém, em Psicanálise é prudente suspeitar de "melhoras rápidas e milagrosas". Já na segunda semana havia fortes traços da "antiga Beth". Foi quando entendemos que o processo de se implicar/ não se implicar no tratamento, aceitar/não aceitar o berço novinho, era seu modo de ser no mundo, a forma contraditória de seu desejo. E era exatamente com isto que teríamos que lidar, este era o sintoma, esta era a patologia. O tratamento havia se iniciado. 